\title{
DETEKSI KELAYUAN BUNGA MAWAR DENGAN METODE TRANSFORMASI RUANG WARNA HSI DAN HSV
}

\author{
Dede Wandi ${ }^{1}$, auziah $^{2}$, Nur Hayati ${ }^{3}$ \\ Informatika, Fakultas Teknologi Komunikasi dan Informatika, Universitas Nasional \\ dedewandi5@gmail.com¹, fauziah@civitas.unas.ac.id ${ }^{2}$,nurhayati@civitas.unas.ac.id ${ }^{3}$
}

Submitted January 8, 2021; Revised April 1, 2021; Accepted April 1, 2021

\begin{abstract}
Abstrak
Bunga mawar merupakan tanaman dari genus Rosa yang memilik lebih dari 100 spesies dengan berbagai warna. Pada proses pemilihan bunga mawar akan ditemukan bunga mawar yang masih segar dan layu. Dengan itu kita dapat mendeteksi kelayuan bunga mawar dengan menerapkan metode HSI dan HSV pada aplikasi pengolahan citra, proses pengambilan data yaitu dengan melakukan preparasi data pada dataset kaggle yang kemudian dilakukan klasifikasi dan training data dengan menggunakan metode HSI dan HSV. Berdasarkan hasil klasifikasi dari total 820 gambar citra bunga mawar dilakukan pengujian sebanyak 757 gambar dengan menggunakan HSI dan HSV didapat nilai Range pada HSI, $\mathrm{H}=0-0.5, \mathrm{~S}=0-1$, dan $\mathrm{I}=0.5372549-1$ dengan kategori Segar, sedangkan kategori Layu HSI, $\mathrm{H}=0-0.5, \mathrm{~S}=0-1, \mathrm{I}=0.5620915-1$. Adapun nilai range HSV dengan kategori Segar $\mathrm{H}=0-0.5, \mathrm{~S}=0-1$, $\mathrm{V}=0-1$, dan kategori Layu $\mathrm{H}=0-0.5, \mathrm{~S}=0-1, \mathrm{~V}=0-1$. Selanjutnya tingkat keberhasilan untuk pengujian bunga mawar dengan HSI mencapai 92.3\% dimana data yang terbaca benar 757 dan terbaca salah 63 dari 820 data sampel bunga mawar, sedangkan pengujian pada HSV tingkat keberhasilan mencapai 93.2\% dimana data yang terbaca benar 765 dan terbaca salah 55 dari 820 data sampel bunga mawar. Berdasarkan hasil diatas deteksi kelayuan bunga mawar dengan metode transformasi ruang warna HSV merupakan yang terbaik pada pengujian data.
\end{abstract}

Kata Kunci : deteksi kelayuan; pengolahn citra; HSI; HSV; klasifikasi.

\begin{abstract}
The rose is a plant from the genus Rosa which has more than 100 species with various colors. In the process of selecting roses, you will find roses that are still fresh and wilted. With that, we can detect the wilting of the rose by applying the HSI and HSV methods to image processing applications, the data collection process, namely by making data preparations on the Kaggle dataset, then classifying and training the data using the HSI and HSV methods. Based on the classification results of a total of 820 images of rose images, a total of 757 images were tested using HSI and HSV. The values obtained were Range at HSI, $H=0-0.5, S=0-1$, and $I=0.5372549-1$ in the Fresh category, while the category HSI wilt, $H=0-0.5, S=0-1, I=0.5620915-1$. The HSV range values are in the Fresh category $H=0-0.5, S=0-1, V=0-1$, and the Wilt category $H=0-0.5, S=0-1, V=0-1$. Furthermore, the success rate for testing roses with HSI reached $92.3 \%$ where the data read correctly 757 and read incorrectly 63 out of 820 sample data of roses, while testing on HSV the success rate reached 93.2\% where the data read correctly 765 and read incorrectly 55 out of 820 rose flower sample data. Based on the above results, detection of wilting roses using the HSV color space transformation method is the best in data testing.
\end{abstract}

Key Words : withering detection; image processing; HSI; HSV; classification.

\section{PENDAHULUAN}

Salah satu kekayaan flora yang ada di Indonesia adalah bunga mawar dari genus Rosa yang terdiri dari 100 spesies lebih dengan berbagai warna. Pada proses pemilihan bunga mawar biasanya ditemukan bunga yang segar dan layu. Kelayuan pada bunga bisa dilihat dari tekstur warna pada bunga tersebut, setiap bunga mawar memiliki warna kelayuan yang berbeda dengan itu harus dilakukan segmentasi warna pada bunga yang 
merupakan pemisahan segmen dalam suatu citra berdasarkan warna yang terkandung dalam citra [1]. Citra yang kaya dengan informasi memiliki karakterisitik yang tidak dimiliki oleh data teks [2].

Perlu dilakukan untuk pemilihan kelayuan pada bunga dengan tujuan dari penelitian ini adalah menemukan parameter terkait warna kelayuan dengan proses ekstraksi fitur dalam segmentasi ruang warna HSI dan HSV. Harapannya bahwa parameter ini dapat dijadikan sebagai set poin untuk melakukan proses deteksi kelayuan yang dapat dikombinasikan dengan metode pengolahan citra lainnya dengan objek tetap warna kelayuan pada bunga mawar.

Pada penelitian sebelumnya oleh Fitri dan Abdul dengan "Sistem Pengenalan Bunga Berbasis Pengolahan Citra dan Pengklasifikasi Jarak" memperoleh tingkat akurasi tertinggi $85 \%$ dengan metode jarak manhattan dengan ektraksi ciri histogram dan paling rendah tingkat akurasinya sebesar 77\%, menggunakan metode klasifikasi Euclidean [3]. Penelitian tentang deteksi menggunakan transformasi warna HSI telah dilakukan oleh Edha dengan judul "Penerapan Metode Transformasi Ruang Warna Hue Saturation Intensity (HSI) Untuk Mendeteksi Kematangan Buah Mangga Harum Manis" [4]. Hasil penelitiannya mendapatkan hasil presentasi yang baik yaitu $87 \%$ pada tingkat keberhasilannya. Dan penelitian tentang deteksi menggunakan transformasi warna HSV oleh Nina dengan judul "Identifikasi Tingkat Kematangan Buah Pisang Menggunakan Metode Ektraksi Ciri Statistik Pada Warna Kulit Buah" [5]. Dengan tingkat presentasi keberhasilan sebesar $90 \%$.

Pada Penelitian Rianto dan Harjoko "Penentuan Kematangan Buah Salak Pondoh Di Pohon Berbasis Pengolahan Citra Digital" yang menggunakan metode segmentasi warna RGB dan gray, serta $K$ -
Nearest Neighbor dengan mengetahui nilai mean $\mathrm{R}$ dan mean $\mathrm{V}$ yang dimana setiap piksel buah salak pondoh dihitung besar ketidak miripannya terhadap nilai data fitur RGB dan gray pembanding kemudian di klasifikasi [6]. Dan penelitian Lestary pada "Deteksi Penyakit Tanaman Jeruk Siam Berdasarkan Citra Daun Menggunakan Segmentasi Warna RGBHSV" dengan pengklasifikasikan jenis penyakit pada daun jeruk menggunakan Fuzzy K-Nearest Neighbor [7].

Untuk proses pemilihan bunga dapat menerapkan metode Hue Saturation Intensity (HSI) dan Hue Saturation Value (HSV) pada aplikasi pengolahan citra. Model HSI memiliki kemampuan untuk memisahkan intensitas informasi intrinsik warna, yang mengacu pada Hue dan Saturation, sedangkan proses HSV didasarkan pada ciri warna bunga mawar dengan mengambil nilai RGB (Red, Green, dan Blue) pada citra. Model ini cocok untuk mengolah citra yang menghadirkan perubahan pencahayaan, karena disebabkan warna lingkungan dapat dibedakan satu sama lain melalui komponen Hue [8] yang bertujuan untuk menentukan kelayuan pada bunga mawar tersebut, dengan membatasi permasalahnya hanya mendeteksi kelayuan pada bunga mawar dengan metode HSI dan HSV, dengan menggunakan K-NN untuk klasifikasi data baru berdasarkan jarak terdekat ke sejumlah data latih [9].

Pembuatan sistem pengolah citra untuk mendeteksi kelayuan dibuat dengan pengolahan citra pada matlab, bermacamacam pengolahan gambar warna salah satunya model rgb atau normalisasi RGB. Model pengolahan citra ini merupakan pengolahan warna dengan menghitung prosentase warna RGB dalam sebuah citra [10]. Proses segmentasi merupakan proses pemisah bagian dalam citra untuk mendapatkan hasil pengenalan objek yang akurat [11]. model yang dibentuk model 
RGB merupakan hasil campuran dari warna primer [12].

\section{METODE PENELITIAN}

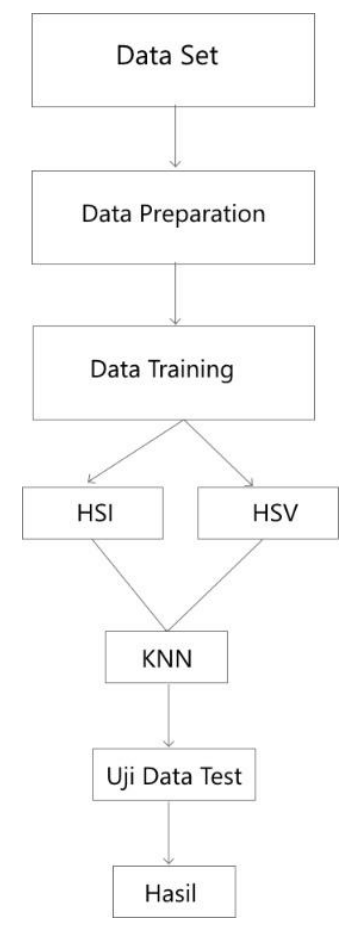

\section{Gambar 1. Tahapan Penelitian Pada Deteksi Kelayuan}

Tahapan diatas menjelaskan alur dari proses kompresi citra pertama dilakukan pengumpulan data set yang akan diuji pada sistem, dalam pengumpulan data set ini dibuat dengan data gambar bunga layu dan segar. Dalam prosesnya dilakukan preparasi data gambar pada kaggle untuk mendapatkan data gambar bunga mawar yang segar dan layu. Pengelompokan yang jadikan sebagai data uji dan data latih untuk mendapatkan nilai HSI dan HSV.

Selanjutnya training data gambar uji bunga mawar dengan metode HSI dan HSV, Pada HSI yaitu dilakukan training data dari RGB ke HSI. Warna dasar pada RGB merupakan warna yang dijadikan patokan yang warnanya akan tampil secara universal yang warnanya bisa diubah kedalam kode-kode [13]. Dengan rumus menghitung nilai rgb dalam bentuk normalisasi:

$$
\mathrm{R}=\frac{R}{(\mathrm{R}+\mathrm{G}+\mathrm{B})} \mathrm{g}=\frac{G}{(\mathrm{R}+\mathrm{G}+\mathrm{B})} \mathrm{b}=\frac{B}{(\mathrm{R}+\mathrm{G}+\mathrm{B})}
$$

Pada rumus diatas dibuat kedalam program matlab untuk mengahasilkan nilai dari RGB tersebut.

Pada Rumus Hue dihitung dengan menggunakan rumus

$$
\begin{gathered}
\theta=\cos -1\left\{\frac{\frac{1}{2}[(\mathrm{R}-\mathrm{G})+(\mathrm{R}-\mathrm{B})]}{\left[(\mathrm{R}-\mathrm{G})^{2}+(\mathrm{R}-\mathrm{B})(\mathrm{G}-\mathrm{B})\right] \frac{1}{2}}\right\} \\
\mathrm{H}=\left\{\begin{array}{cl}
\theta & \text { Jika } B \leq G \\
360 \theta & \text { Jika } B>G
\end{array}\right.
\end{gathered}
$$

Pada komponen saturation dihitung dengan menggunakan rumus :

$\mathrm{S}=1-\frac{3}{\min (\mathrm{R}, \mathrm{G}, \mathrm{B})} \min (R, G, B)$

Menghitung nilai intensity

$I=\frac{1}{2}(R+G+B)$

Dengan rumus $1-4$, dibuat kedalam sebuah program matlab untuk dicari nilai HSI yang dihasilkan.

Pada perhitungan HSV dilakukan dengan menganalisis nilai warna tiap piksel citra sesuai fitur yang diinginkan dengan nilai toleransi pada setiap dimensi warna HSV [14]. Untuk menghitung normalisasi RGB sama seperti pada rumus 1. Untuk menghitung nilai Hue pada HSV

$$
\begin{gathered}
\theta \\
=\cos -1\left\{\frac{\frac{1}{2}[(\mathrm{R}-\mathrm{G})+(\mathrm{R}-\mathrm{B})]}{\left[(\mathrm{R}-\mathrm{G})^{2}+(\mathrm{R}-\mathrm{B})(\mathrm{G}-\mathrm{B})\right] \frac{1}{2}}\right\} \\
\mathrm{H}=\left\{\begin{array}{cc}
\theta & \text { Jika } B \leq G \\
360 \theta & \text { Jika } B>G
\end{array}\right.
\end{gathered}
$$

Menghitung nilai Value:

$$
V=\max (r, g, b)
$$

Menghitung nilai Saturasi:

$$
\mathrm{S}= \begin{cases}\theta & \text { Jika } V=0 \\ 1-\frac{\min (\mathrm{r}, \mathrm{g}, \mathrm{b})}{\mathrm{v}} & \text { Jika } V>0\end{cases}
$$


Untuk mencari nilai HSV dari rumus 5-7, sama dibuat kedalam sebuah program matlab untuk dicari nilai HSV yang dihasilkan.

Selanjutnya menentukan klasifikasi setiap hasil yang diperoleh dengan metode $K$ Nearest Neighbor (KNN), metode ini melakukan klasifikasi terhadap objek nilai warna yang telah dihasilkan berdasarkan data pembelajaran yang telah di ektraksi. KNN menggunakan data pembelajaran dengan jarak yang akan dievaluasi dengan $\mathrm{k}=\mathrm{n}$ [15]. Yang nantinya untuk diklasifikasikan pada objek baru yang berdasarkan atribut dan data training sample yang akan diuji.

Sebelum dilakukan perhitungan, terlebih dahulu harus menentukan data latih dan data uji. KNN merupakan metode yang digunakan untuk pencarian, klasifikasi, klustering [16].

$$
d i=\sqrt{\sum_{1}^{n}=i^{(x 1 i-x 2 i)^{2}}}
$$

Rumus KNN ini dibuat kedalam program matlab untuk mencari kalisifikasi pada bunga mawar tersebut. Apakah bunga mawar termasuk layu atau segar.

Untuk mengetahui seberapa akurasi data yang sudah ditraining dengan metode HSI dan HSV dilakukan pengujian pada sistem agar output yang dihasilkan bisa sesuai dengan algoritmanya. Data uji test ini dilakukan secara manual dengan 100 data gambar bunga layu dan 100 data gambar bunga segar yang kemudian hasil outputnya akan terbaca salah ataupun benar.

Pada perhitungan uji akurasi pada sistem Menggunakan rumus sebagai berikut:

$$
\text { Akurasi }=\frac{\text { Jumlah Nilai Kebenaran }}{\text { Jumlah Sampel }} \times 100 \%
$$

\section{HASIL DAN PEMBAHASAN}

Dalam tahap pengumpulan data dilakukan proses data preparation yang dimana data gambar diambil dari kaggle yang kemudian dilakukan klasifikasi bunga mawar layu dan segar, kemudian dilakukan training data pada sistem dengan menggunakan HSI dan HSV yang kemudian dilakukan klasifikasi dengan KNN.

Penelitian ini dirancang dengan menggunakan software MATLAB 2017b dengan tampilan GUI. Tampilan yang dibangun pada aplikasi deteksi kelayuan bunga mawar.

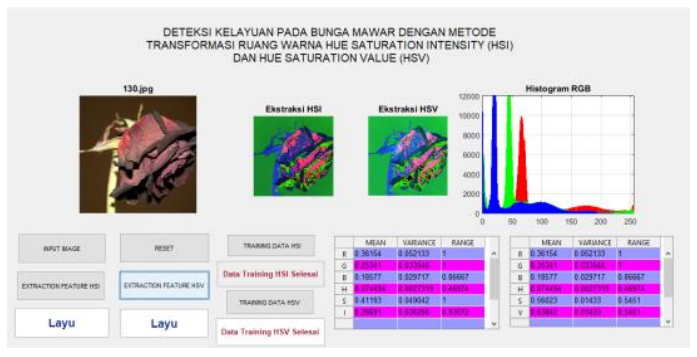

\section{Gambar 2. Tampilan Aplikasi Deteksi Kelayuan Bunga Mawar}

Adapun fitur yang ditampilkan dalam aplikasi yang dirancang diantaranya:

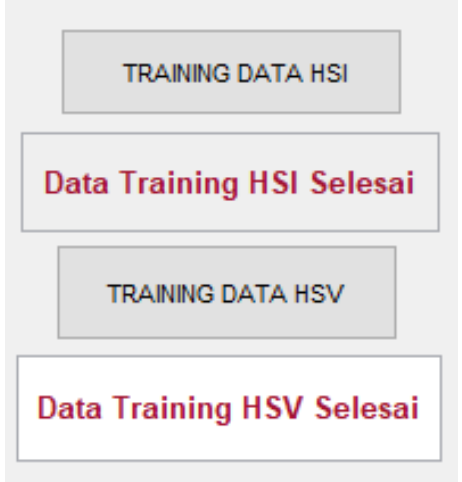

\section{Gambar 3. Data Training HSI dan HSV}

Pada gambar 3 data semua gambar uji akan di training dengan menggunakan algoritma HSI dan algoritma HSV, yang dimana jika data telah selesai di training akan masuk kedalam excel dengan keseluruhan nilai pada masing-masing gambar. 


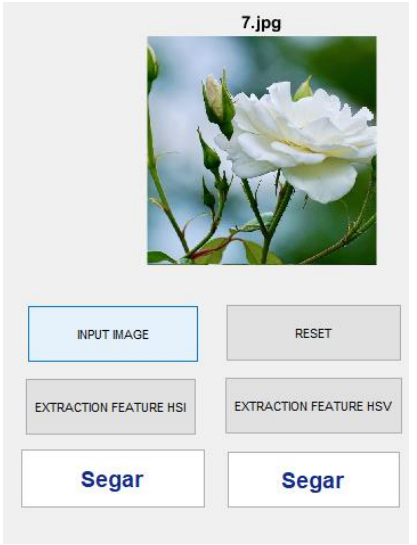

\section{Gambar 4. Ekstraksi Bunga Untuk Mengetahui Jenis Kelayuan}

Pada gambar 4, Input bunga mawar untuk di ektraksi apakah bunga mawar tersebut termasuk ke jenis bunga segar atau layu.
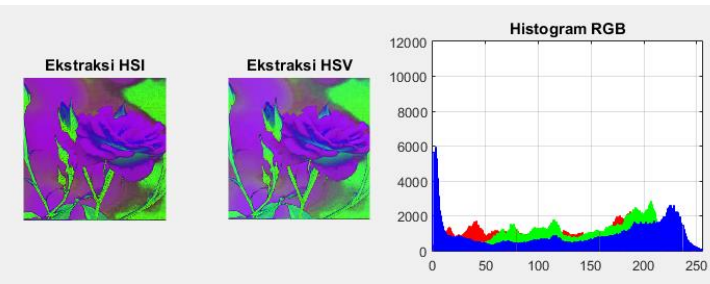

Gambar 5. Ektraksi HSI dan HSV

Pada gambar 5, hasil ektraksi bunga mawar dengan HSI dan HSV dan ditunjukan dengan Hologram RGB dmna besaran nilai RGB pada warna bunga.

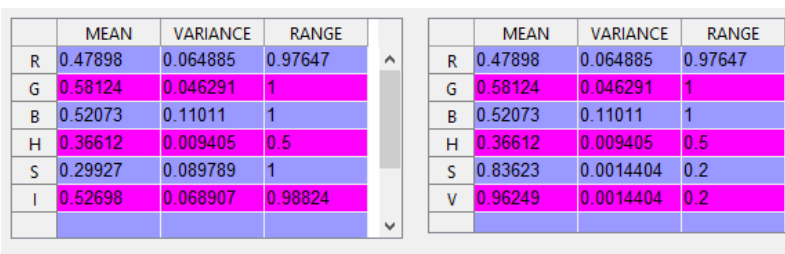

\section{Gambar 6. Hasil Nilai Masing-Masing HSI dan HSV}

Pada gambar 6, memberikan informasi detail nilai RGB HSI dan RGB HSV yang telah di training pada semua gambar uji .

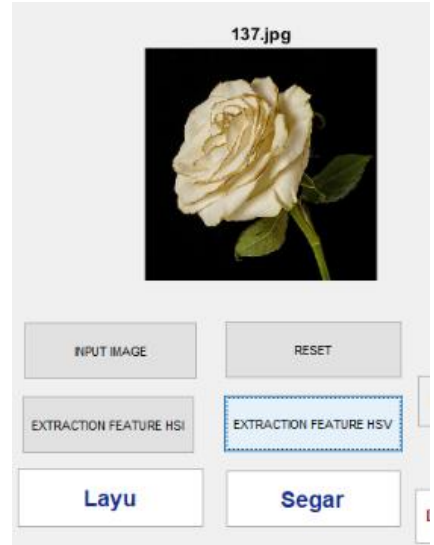

\section{Gambar 7. Hasil Data Uji Test Pada Sistem}

Pada gambar 7, memberikan informasi yang dilakukan pada data uji test bunga mawar segar maupun layu yang hasil pengujiannya akan membaca kebenaran atau kesalahan pada hasil pengujian sistem. Pengujian data test dilakukan pada 200 data uji bunga mawar layu dan segar yang masing-masing diuji test secara manual yang dimana tahapan-tahapan sebelumnya sudah dilakukan sesuai pada gambar 1 .

Test pengujian yang dilakukan pada sistem yang telah dibuat, dilakukan sebanyak 620 data gambar bunga mawar yang diekstraksi dan 200 data gambar sebagai data latih dengan jumlah keseluruhan data 820 gambar. Dengan data uji 268 data gambar bunga layu dan 352 data gambar bunga yang masih segar, yang kemudian dilakukan pengujian terhadap semua data gambar dengan kedua algoritma HSI dan HSV berdasarkan pada ciri warna.

Pada tahap pengujian nilai HSI dan HSV telah didapatkan sesuai dengan program yang dibuat pada matlab sesuai dengan algoritma HSI dan HSV. Lalu dikelompokan secara manual untuk mengetahui nilai Range minimal dan maksimalnya.

Berkut hasil nilai yang telah dilakukan untuk klasifikasi pendeteksian kelayuan pada semua data bunga dengan menggunakan HSI dan HSV. 
Tabel 1. Kelayuan Pada HSI min-max

\begin{tabular}{lccc}
\hline & \multicolumn{2}{c}{ Range HSI } & Kategori \\
\hline $\mathrm{H}$ & 0 & 0.5 & Segar \\
$\mathrm{S}$ & 0 & 1 & \\
$\mathrm{I}$ & 0.5372549 & 1 & \\
\hline $\mathrm{H}$ & 0 & 0.5 & Layu \\
$\mathrm{S}$ & 0 & 1 & \\
$\mathrm{I}$ & 0.5620915 & 1 & \\
\hline
\end{tabular}

Pada tabel 1 menampilkan nilai range HSI dari 352 data segar dan 268 data layu yang didapatkan dari hasil pengujian, dengan kategori nilai segar dan layu yang terdapat pada tabel.

\section{Tabel 2. Kelayuan Pada HSV min-max}

\begin{tabular}{clcc}
\hline & \multicolumn{2}{c}{ Range HSV } & Kategori \\
\hline H & 0 & 0.5 & Segar \\
S & 0 & 1 & \\
V & 0 & 1 & \\
\hline H & 0 & 0.5 & Layu \\
S & 0 & 1 & \\
V & 0 & 1 & \\
\hline
\end{tabular}

Pada tabel 2 menampilkan nilai range HSV dari 352 data segar dan 268 data layu yang didapatkan dari hasil pengujian, dengan kategori nilai segar dan layu yang terdapat pada tabel.

Untuk mendapatkan klasifikasi kelayuan pada bunga dengan KNN dibuat dengan dua data jenis klasifikasi, yang ke 1 segar dan ke 2 Layu. Dengan jumlah nilai rata rata keseluruhan data uji HSI dan HSV.

Sebelum menentukan jarak eucledian dari masing masing data digunakan centroid untuk mencari nilai tersebut.

\section{Tabel 3. Nilai Rata-rata Range HSI}

\begin{tabular}{ccc}
\hline \multicolumn{3}{c}{ Nilai Rata Rata Range } \\
\hline $\mathrm{H}$ & $\mathrm{S}$ & $\mathrm{I}$ \\
0.1517941 & 0.663174 & 0.735293 \\
0.1362126 & 0.712707 & 0.775464 \\
\hline \multicolumn{3}{c}{ Nilai Rata Rata HSI } \\
\hline 0.101259 & 0.246669 & 0.214492 \\
0.103873 & 0.211869 & 0.214859 \\
\hline
\end{tabular}

Tabel 4. Nilai Rata-rata Range HSV

\begin{tabular}{ccc}
\hline \multicolumn{3}{c}{ Nilai Rata Rata Range } \\
\hline $\mathrm{H}$ & $\mathrm{S}$ & $\mathrm{V}$ \\
\hline 0.1574672 & 0.669497 & 0.760778 \\
0.1541355 & 0.68805 & 0.783842 \\
\hline \multicolumn{3}{c}{ Nilai Rata Rata HSV } \\
\hline 0.1012594 & 0.139892 & 0.139892 \\
0.1038731 & 0.125863 & 0.125863 \\
\hline
\end{tabular}

Langkah berikutnya adalah menggunakan perhitungan dari sebelumnya untuk menentukan apakah data uji yang dimasukan termasuk kedalam kategori segar atau layu. Untuk metode KNN adalah dengan menentukan nilai $\mathrm{k}$ terlebih dahulu. Kemudian untuk menentukan klasifikasi berdasarkan dari data latih yang akan dibandingkan dengan data uji. Kemudian akan dicari jarak terdekat dan akan diklasifikasi menurut jarak terdekat tetangga.

\section{KNN HSI}

$$
\begin{aligned}
& (0.1517941-0.101259)^{2}+(0.663174-0.246669)^{2} \\
& +(0.735293-0.139892)^{2} \\
& =0.473213014
\end{aligned}
$$

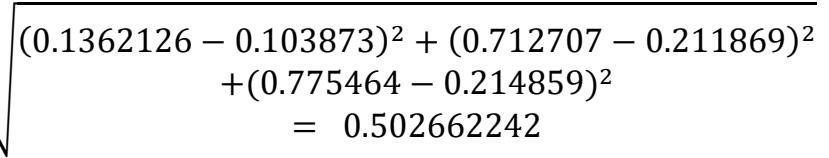

\section{KNN HSV}

$$
\begin{aligned}
& \overline{(0.1574672-0.1012594)^{2}+(0.669497-0.139892)^{2}} \\
& +(0.760778-0.139892)^{2} \\
& =0.276520265
\end{aligned}
$$

$$
\begin{aligned}
& (0.1541355-0.1038731)^{2}+(0.68805-0.125863)^{2} \\
& +(0.783842-0.125863)^{2} \\
& =0.283046561
\end{aligned}
$$

Tabel 5. Klasifikasi HSI

\begin{tabular}{ccc}
\hline $\begin{array}{l}\text { Urutan } \\
\text { Jarak }\end{array}$ & Nilai Jarak & Kelas \\
\hline 1 & 0.473213014 & Segar \\
2 & 0.502662242 & Layu \\
\hline
\end{tabular}


Tabel 6. Klasifikasi HSV

\begin{tabular}{ccc}
\hline $\begin{array}{c}\text { Urutan } \\
\text { Jarak }\end{array}$ & Nilai Jarak & Kelas \\
\hline 1 & 0.276520265 & Segar \\
2 & 0.283046561 & Layu \\
\hline
\end{tabular}

Dari hasil pengujian tersebut didapatkan tingkat keberhasilan untuk pengujian bunga mawar dengan HIS sesuai dengan rumus (9) mencapai $92.3 \%$ dimana data yang terbaca benar 757 dan terbaca salah 63 dari 820 data sampel bunga mawar dengan akurasi kelayuan 91.3\%, dengan 68 data gambar terbaca benar dan 32 data gambar terbaca salah dari 100 data yang gambar kelayuan yang diuji dari 368 data gambar bunga layu dan $93.1 \%$ akurasi kesegaran bunga dari 100 data gambar yang diuji dengan 69 data gambar terbaca benar dan 31 data gambar terbaca salah dari 452 data gambar bunga segar, sehingga menyebabkan tidak terbacanya hasil klasifikasi dikarenakan rendahnya nilai $\mathrm{H}$ (Hue) dan tingginya nilai $\mathrm{S}$ (Saturation). Pada hasil pengujian HSV didapatkan tingkat keberhasilan mencapai 93.2\% dimana data yang terbaca benar 765 dan terbaca salah 55 dari 820 data sampel bunga mawar dengan akurasi kelayuan $92.1 \%$ dari 100 data yang uji 71 data gambar terbaca benar dan 29 data gambar terbaca salah dari 368 data gambar bunga layu dan akurasi kesegaaran bunga mawar $94.2 \%$ dari 100 data gambar yang diuji dengan 74 data gambar terbaca benar dan 26 data gambar terbaca salah dari 452 data gambar bunga segar, sehingga menyebabkan tidak terbacanya hasil klasifikasi dikarenakan rendahnya nilai $\mathrm{H}$ (Hue) dan tingginya nilai V (Value).

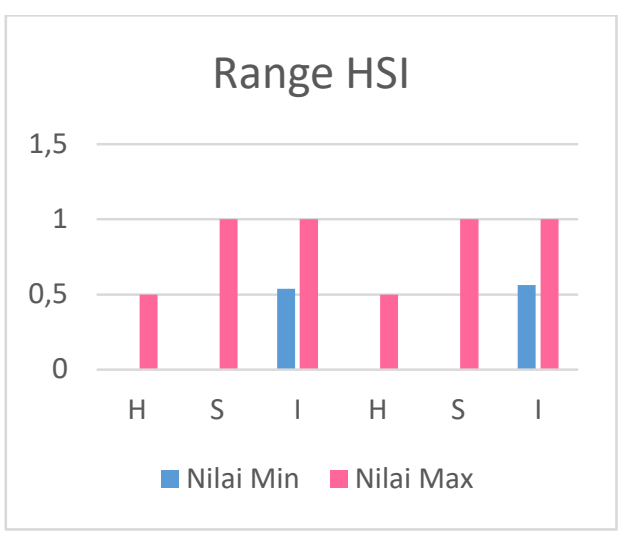

Gambar 8. Diagram Range HSI dengan Pivot

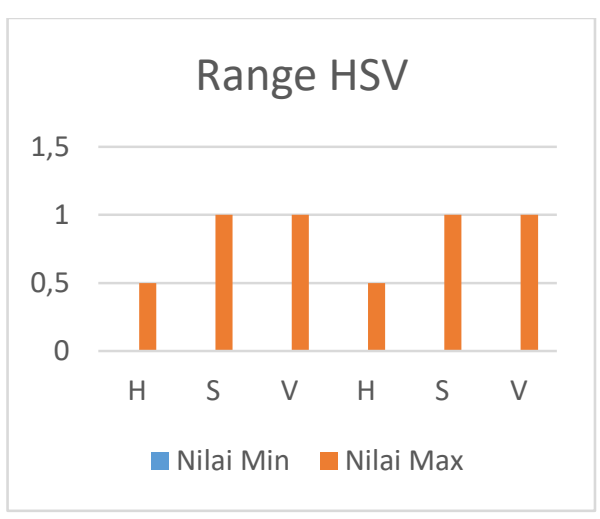

Gambar 9. Diagram Range HSV dengan Pivot

Pada diagram gambar 8 dan 9, memberikan nilai hasil range HSI dan HSV pada kelayuan bunga mawar yang berdasarkan pada warna. Pada diagram gambar 9 yaitu HSV memberikan nilai yang lebih baik diantara nilai min-max dibandingkan dengan HSI.

\section{SIMPULAN}

Untuk mengetahui tingkat kelayuan pada bunga mawar dengan menerapkan metode HSI dan HSV berdasarkan pada warna maka dapat disimpulkan dari total 820 gambar citra bunga mawar yang diuji 757 gambar dengan menggunakan HSI dan HSV didapat nilai Range pada $\mathrm{HSI}, \mathrm{H}=0$ 0.5 , $\mathrm{S}=0-1$, dan $\mathrm{I}=0.5372549-1$ dengan kategori Segar, sedangkan kategori Layu HSI, $\mathrm{H}=0-0.5, \mathrm{~S}=0-1, \mathrm{I}=0.5620915-1$. 
Adapun nilai Range HSV dengan kategori Segar $\mathrm{H}=0-0.5, \quad \mathrm{~S}=0-1, \quad \mathrm{~V}=0-1$, dan kategori Layu $\mathrm{H}=0-0.5, \mathrm{~S}=0-1, \quad \mathrm{~V}=0-1$. Dengan tingkat keberhasilan untuk pengujian bunga mawar dengan HSI mencapai $92.3 \%$ dimana data yang terbaca benar 757 dan terbaca salah 63 dari 820 data sampel bunga mawar dengan akurasi kelayuan $91.3 \%$, dengan 68 data gambar terbaca benar dan 32 data gambar terbaca salah dari 100 data yang gambar kelayuan yang diuji dari 368 data gambar bunga layu dan $93.1 \%$ akurasi kesegaran bunga dari 100 data gambar yang diuji dengan 69 data gambar terbaca benar dan 31 data gambar terbaca salah dari 452 data gambar bunga segar. Pada pengujian HSV tingkat keberhasilan mencapai $93.2 \%$ dimana data yang terbaca benar 765 dan terbaca salah 55 dari 820 data sampel bunga mawar dengan akurasi kelayuan $92.1 \%$ dari 100 data yang uji 71 data gambar terbaca benar dan 29 data gambar terbaca salah dari 368 data gambar bunga layu dan akurasi kesegaaran bunga $94.2 \%$ dari 100 data gambar yang diuji dengan 74 data gambar terbaca benar dan 26 data gambar terbaca salah dari 452 data gambar bunga segar. Maka dari itu dapat disimpulkan bahwa deteksi kelayuan pada bunga mawar dengan metode transformasi ruang warna HSI (Hue Saturation Intensity) dan HSV (Hue Saturation Value) yang baik dalam prosesnya adalah menggunakan metode HSV.

\section{DAFTAR PUSTAKA}

[1] B. Yoga et al., "Segmentasi warna citra dengan deteksi warna hsv untuk mendeteksi objek," J. Inform., vol. 6, no. 2, 2010.

[2] Y. Permadi and Murinto, "Aplikasi Pengolahan Citra Untuk Identifikasi Kematangan Mentimun Berdasarkan Tekstur Kulit Buah Menggunakan Metode Ekstraksi Ciri Statistik," J. Inform., vol. 9, no. 1, pp. 10281038, 2015.
[3] F. Muwardi and A. Fadlil, "Sistem

Pengenalan Bunga Berbasis

Pengolahan Citra dan

Pengklasifikasi Jarak," J. Ilm. Tek.

Elektro Komput. dan Inform., vol. 3, no. 2, p. 124, 2018, doi: 10.26555/jiteki.v3i2.7470.

[4] H. Edha, S. H. Sitorus, U. Ristian, J. Rakayasa, and S. Komputer, "Penerapan Metode Transformasi Ruang Warna Hue Saturation Intensity (HSI) Untuk Mendeteksi Kematangan Buah Mangga Harum Manis," J. Komput. dan Apl., vol. 08, no. 1, pp. 1-10, 2020.

[5] N. Sularida, J. Y. Sari, I. Purwanti, and N. Purnama, "Identifikasi Tingkat Kematangan Buah Pisang Menggunakan Metode Ektraksi Ciri Statistik Pada Warna Kulit Buah," ULTIMATICS, vol. X, no. 2, 2018, doi: 10.31937/ti.v10i2.1004.

[6] P. Rianto and A. Harjoko, "Penentuan Kematangan Buah Salak Pondoh Di Pohon Berbasis Pengolahan Citra Digital," IJCCS (Indonesian J. Comput. Cybern. Syst., vol. 11, no. 2, p. 143, 2017, doi: 10.22146/ijccs.17416.

[7] F. R. Lestari, J. Y. Sari, Sutardi, and I. Purwanti, "Deteksi Penyakit Tanaman Jeruk Siam Berdasarkan Citra Daun Menggunakan Segmentasi Warna RGB-HSV," no. December, pp. 276-283, 2018.

[8] E. Blotta, A. Bouchet, V. Ballarin, and J. Pastore, "Enhancement of medical images in HSI color space," J. Phys. Conf. Ser., vol. 332, no. 1, 2011, doi: 10.1088/17426596/332/1/012041.

[9] A. Qur'ania, L. Karlitasar, and S. Maryana, "Analisis Tektur Dan Ekstraksi Fitur Warna Untuk Klasifikasi Apel Berbasis Citra," pp. 296-304, 2012.

[10] A. N. T. RD. Kusumanto, "Pengolahan Citra Digital Untuk 
Mendeteksi Obyek Menggunakan Pengolahan Warna Model Normalisasi Rgb," Semin. Nas. Teknol. Inf. Komun. Terap. 2011, 2011, doi: 10.1016/S01661116(08)71924-1.

[11] A. K. Panggabean, A. Syahfaridzah, and N. A. Ardiningih, "Mendeteksi Objek Berdasarkan Warna Dengan Segmentasi Warna HSV Menggunakan Aplikasi Matlab," METHOMIKA J. Manaj. Inform. Komputerisasi Akunt., vol. 4, no. 2, pp. 94-97, 2020.

[12] Y. K. Arinda, M. A. Rahman, and D. Alamsyah, "Klasifikasi Jenis Bunga menggunakan SVM dengan Fitur HSV dan HOG," Ijccs, no. x, pp. 1-12, 2018.

[13] R. Pratama, A. F. Assagaf, and F. Tempola, "Deteksi Kematangan Buah Tomat Berdasarkan Fitur Warna Menggunakan Metode
Transformasi Ruang Warna HIS," JIKO (Jurnal Inform. dan Komputer), vol. 2, no. 2, pp. 81-86, 2019, doi: http://dx.doi.org/10.33387/jiko.

[14] N. Arifin and I. S. Areni, "Klasifikasi Kematangan Stroberi Berbasis Segmentasi Warna dengan Metode HSV," vol. 23, no. 2, pp. 113-116, 2019, doi: 10.25042/jpe.112019.03.

[15] H. Risman, D. Nugroho, and Y. R. WU, "Penerapan Metode K-Nearest Neighbor Pada Aplikasi," Jural TIKomSiN, vol. 3, no. 2, pp. 19-25, 2013.

[16] N. K. S. Ningrum and T. Ellen, "Ekstraksi Warna Berdasarkan Rgb Untuk Menentukan Tingkat Kematangan Daun Tembakau," Pros. SNATIF Ke -5 Tahun 2018, pp. 96-101, 2019. 